\title{
DETERMINATION OF THE MECHANICAL PROPERTIES OF THE LIGHTWEIGHT ABLATIVE MATERIAL ZURAM
}

\author{
Thomas Reimer ${ }^{1}$, Christian Zuber ${ }^{1}$, Jakob Rieser ${ }^{1}$, Thomas Rothermel $^{1}$ \\ ${ }^{1}$ DLR, German Aerospace Center, Institute of Structures and Design \\ Pfaffenwaldring 38-40, 70569 Stuttgart, Germany
}

\begin{abstract}
The ablative material ZURAM has been developed by the German Aerospace Center DLR. It is manufactured from a rigid carbon felt impregnated with phenolic resin. It has a low density of approximately $0.36-0.4 \mathrm{~g} / \mathrm{cm}^{3}$. Arc jet tests were carried out up to heat fluxes of 13.5 $\mathrm{MW} / \mathrm{m}^{2}$ indicating the potential of the material with recession rates of approximately $0.3 \mathrm{~mm} / \mathrm{s}$. To characterize the material in detail to facilitate the design for space vehicles, the complete set of thermal and mechanical material properties has to be established. This paper will present the determination of the mechanical properties related to the microstructure. A characterization in tension, compression and shear was carried out resulting in the respective moduli and strength values. It was found that the material has an anisotropic behavior. Since the material is rather delicate in comparison to other structural materials, stress and strain measurements were in part also based on optical measurements to not disturb the material response.
\end{abstract}

\section{INTRODUCTION}

A spacecraft entering into the atmosphere of Earth or another planet has to withstand severe heat loads which depend on factors like entry speed, entry angle, vehicle geometry and mass and also the type of atmosphere. A heat shield is used to protect vehicles from the resulting high heat loads ${ }^{1}$. There are different concepts of heat shields that are used to fulfill the task. Reusable systems like the heat shield of the Space Shuttle bear the heat load without changing their shape or losing mass which is a good thing with respect to aerodynamics. The disadvantage of such systems is that they are limited with respect to their use temperature. This is due to the materials. The Shuttle TPS e.g. was partially made from carbon-carbon, a ceramic matrix composite (CMC) with a protective coating, which is in addition relatively expensive to manufacture and maintain ${ }^{2}$.

Ablators are currently the thermal protection system of choice when the heat loads become extremely high or simply too high for reusable systems as e.g. in the case of a superorbital entry as in the case of a moon or mars return ${ }^{3,4}$. A complex set of processes takes place when ablative materials are heated up ${ }^{5}$. Part of the incoming heat is rejected via surface radiation due to the high surface temperature as is the case with re-usable systems, but there are also other processes that consume heat as a result of material transformation. Energy consumption takes place due to chemical processes like pyrolysis and physical change. In addition there is film cooling due to outgassing and also radiation blocking because of particles transported into the boundary layer.

The materials undergo massive changes and lose a considerable share of their initial thickness. The decrease of the ablator thickness, respectively the recession, is a critical issue for the design of an ablative heat shield because for a given mission the remaining thickness has to be sufficient to guarantee the effective function as a heat shield. The investigation of ablative materials with regard to their recession is carried out in arc jet facilities ${ }^{6}$. Also very important is the issue of the mechanical properties of the ablative material, especially when considering the possibly large recession rates ${ }^{6}$. The ablator is the heat shield element that has to bear the aerodynamic loads and transmit those loads to the underlying structure of the spacecraft. So it is 
mandatory to have an exact knowledge of the properties to be able to arrive at a sound heat shield design ${ }^{7,8}$. This point becomes more important with increasing heat shield size.

The present work aims at describing how the mechanical properties of the ZURAM material were determined for tension, compression and shear.

\section{MATERIAL DESCRIPTION AND PROCESSING}

ZURAM is a lightweight ablative material with a density of $0.36-0.4 \mathrm{~g} / \mathrm{cm}^{3}$, designed for high enthalpy entry missions. The base material is CALCARB, a non-flexible industrial grade carbon-fiber felt used as thermal insulation in production furnaces. CALCARB has been used before as a simple replacement of ablators to investigate recession phenomena ${ }^{9}$. Employing a specific process, a nanoscale phenolic foam is created via infiltration of the felt with liquid phenolic resin and subsequent polymerization. Thus the base type of material used for the presented investigations is called ZURAM 18/50 which corresponds to a CALCARB density of $0.18 \mathrm{~g} / \mathrm{cm}^{3}$ and the number of 50 related to the matrix resin.

Although CALCARB is produced from chopped short fibers, it shows a distinct fiber orientation. The material is supplied in the form of boards and by observation it can be noticed that there is a preferred direction for the fibers in the in-plane direction of the boards.

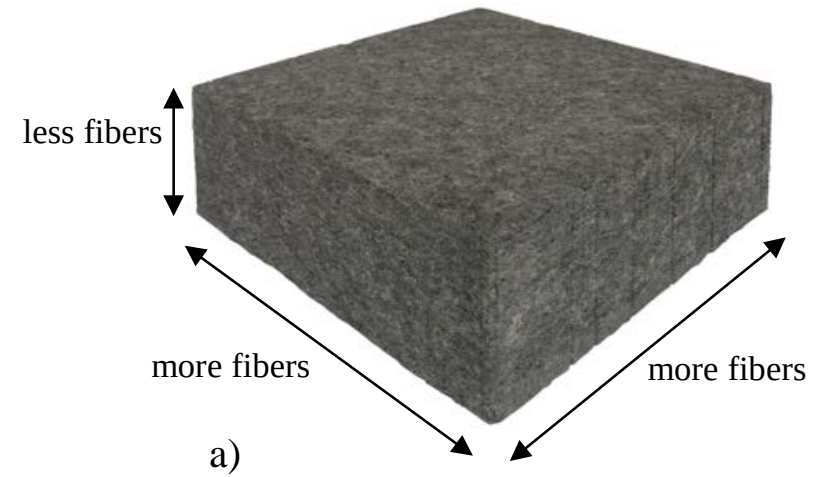

Figure 1: a) carbon fiber preform b) as-manufactured block of ZURAM.

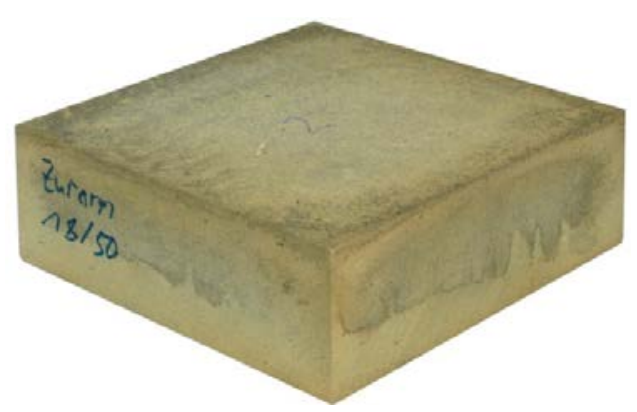

b)

In arc jet tests at enthalpies of $13.5 \mathrm{MW} / \mathrm{m}^{2}$ and a pressure of $675 \mathrm{hPa}$, average values for the mass loss and ablation rate were $0.323 \mathrm{~g} / \mathrm{s}$ and $0.308 \mathrm{~mm} / \mathrm{s}$ respectively. In another work the recession rate of Zuram was investigated in-situ via optical methods in arc jet tests generating results resolved over space and time ${ }^{10}$. The thermal conductivity of the uncharred material is approximately $0.18 \mathrm{~W} / \mathrm{mK}$ at ambient conditions.

\section{METHODOLOGY DESCRIPTION}

Compression tests were carried out to start with the least complex setup. The tests were done with the load direction perpendicular to the fiber direction. From these tests, the compression modulus, the poisson numbers and the compression strength in the relevant direction were obtained. Shear tests were following to achieve shear modulus and shear strength in the plane of the main fiber direction.

Following were tensile tests, where the sample geometry is more complex and generates challenges for the load introduction, but as well for the determination of failure strains. In the case of the tensile testing, tests were done in the direction of the main fiber direction in the material but also perpendicular to that. In order to support the investigation, the tensile tests were also re-built numerically using the ANSYS finite elemente software to determine the failure strain and stress at the failure location of the waisted specimens. In order to be able to do this the necessary material characteristics had to be established first in the compression and shear tests as 
far as possible. Then the numerical investigation was an iterative procedure because not all data was known in advance. Finally, tension tests were carried out with the load in the direction normal to the main fiber direction. Shear tests with the shear plane normal to the main fiber direction have yet to be done to have all load directions for tension, compression and shear covered.

\section{OPTICAL DEFORMATION AND STRAIN MEASUREMENT}

The data acquisition of the tests was supported by using the optical method of photogrammetry for the measurement of deformation and strain. It can be applied as a two- or three-dimensional method. In this case the choice was for the 2-D variant, since the samples were suitable and the processing is easier and faster.

The photogrammetric system was the commercial product ARAMIS V6 from the company GOM. The images were taken with a Canon EOS 60D DSLR camera. Every second one image was taken. The image size was originally 5184x3456 pixel but was downsized to $2592 \times 1728$ pixel. The reason for not using the ARAMIS system cameras was, that it had a resolution of only $1 \mathrm{MP}$. The reason for downsizing the images from the DSLR camera was to achieve reasonable computing times. The samples had to be prepared with a dot pattern which is used by ARAMIS to trace surface features of the sample. The pattern has to be irregular and characteristic and to achieve this the samples were sprayed with black paint.

The motivation for using the photogrammetry was based on several issues. In some test set-ups the machine travel is unreliable because it integrates over a large distance including not only the sample but also clamps, fixtures and machine frame. In addition, to determine poisson numbers, usually strain gauges are used to acquire the strain perpendicular to the load direction. In the case of a material like ZURAM, which is quite delicate with a high degree of porosity, strain-gauges cannot be used because they are intrusive and falsify the results due to the required adhesive which fills up pores adjacent to the strain gauge and thus lead to a local stiffening of the material.

\section{COMPRESSION TESTS PERPENDICULAR TO THE FIBER DIRECTION}

The samples were of cylindrical shape with a diameter of $20.4 \mathrm{~mm}$ and a height of $45 \mathrm{~mm}$. The samples were taken out of a machined block of $45 \mathrm{~mm}$ thickness via core drilling.

Table 1: Samples for compression tests

\begin{tabular}{cccccc}
\hline \hline Sample & Diameter & Height & Mass & Density & $\begin{array}{c}\text { rel. density } \\
\text { variation }\end{array}$ \\
\hline Z\#7 & $\mathrm{mm}$ & $\mathrm{mm}$ & $\mathrm{g}$ & $\mathrm{kg} / \mathrm{m}^{3}$ & $\%$ \\
Z\#8 & 20.58 & 45.00 & 6.31 & 421.54 & 5.61 \\
Z\#9 & 20.58 & 45.07 & 6.07 & 404.87 & 1.43 \\
Z\#10 & 20.57 & 45.03 & 5.65 & 377.56 & -5.41 \\
Z\#11 & 20.57 & 45.06 & 6.43 & 429.40 & 7.58 \\
Z\#12 & 20.57 & 45.07 & 5.60 & 373.89 & -6.32 \\
Z\#M & 20.60 & 45.00 & 5.51 & 367.38 & -7.96 \\
\hline Average & 20.40 & 45.02 & 6.17 & 419.30 & 5.05 \\
\hline \hline
\end{tabular}

The data of the samples for the compression tests is given in detail to highlight the density variation that was determined. Related to the average value of the compression samples of $399.13 \mathrm{~kg} / \mathrm{m}^{3}$, there was a variation of roughly $+/-8 \%$. This can be mainly attributed to a variation in the carbon felt preform as will be later detailed. 
The tests were conducted in a Zwick-Roell $250 \mathrm{kN}$ mechanical test machine. The Test velocity was $1 \mathrm{~mm} / \mathrm{min}$ with displacement as the control parameter. A pre-load of $3 \mathrm{~N}$ was applied. The tests were conducted in the mechanical test lab in controlled conditions. The test settings included 3 steps of $10 \mathrm{~mm}$ for each step resulting in little dents in the force-displacement graphs. Of the 7 tests conducted, 5 were accepted as valid. In Figure 2, the graphs of the compression tests are shown in one plot.

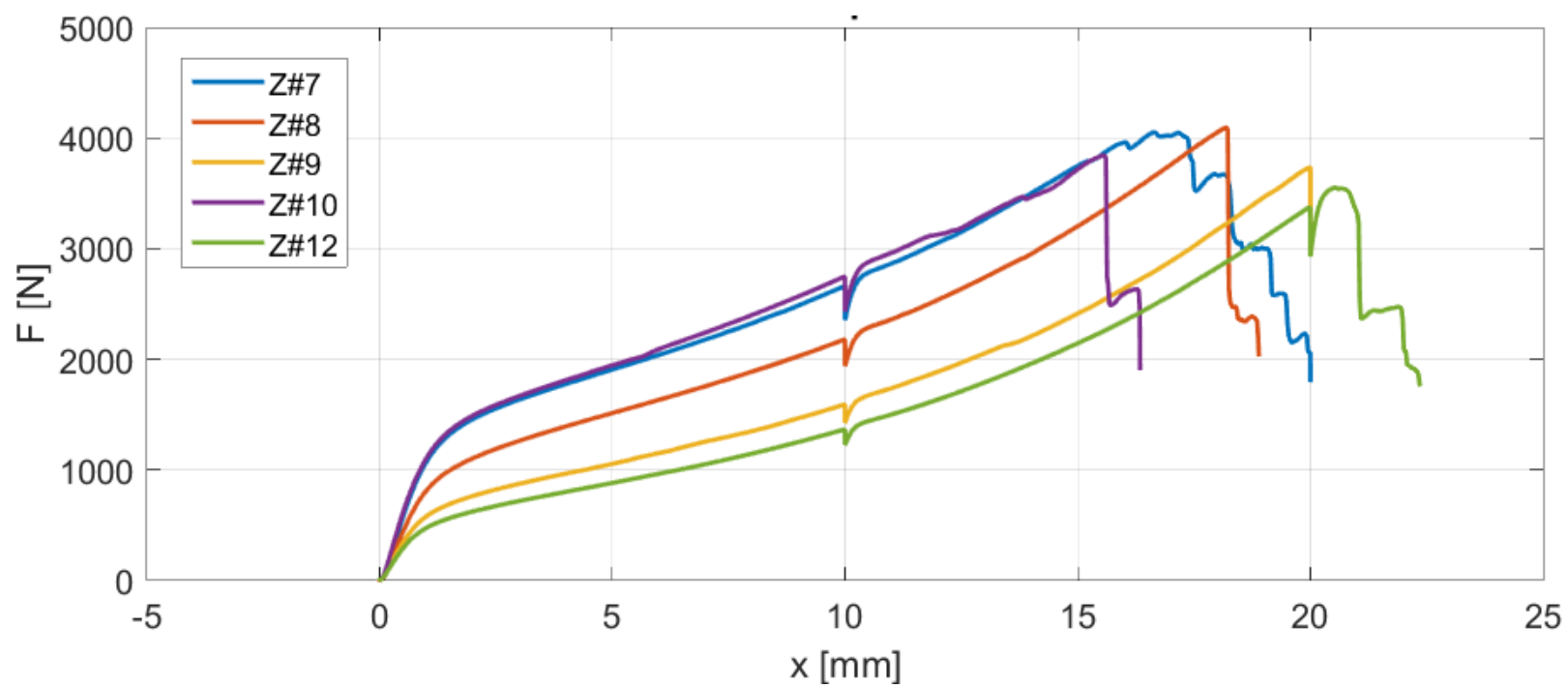

Figure 2: Force-displacement graphs of the compression tests.

The samples showed a lot of plastic deformation of up to $20 \mathrm{~mm}$ and finally failure was typically occurring with an angled sliding fracture.

The limitation of the linear-elastic behavior was defined by the second derivative of the force change over time being smaller than 0.2 which means that the slope of the force change shall be near zero. The results of the compression tests with the fibers perpendicular to the load direction are listed in Table 2.

Table 2: Results of the compression tests.

\begin{tabular}{ccccccc}
\hline \hline Sample & $\mathrm{F}_{\mathrm{m}}$ & $\mathrm{A}_{0}$ & $\sigma_{\mathrm{c}, \mathrm{e}}$ & $\varepsilon_{\mathrm{c}, \mathrm{e}}$ & $\sigma_{\mathrm{c}, \mathrm{p}}$ & $\mathrm{E}_{\mathrm{c}, \mathrm{e}}$ \\
\hline & $\mathrm{N}$ & $\mathrm{mm}^{2}$ & $\mathrm{MPa}$ & $\%$ & $\mathrm{MPa}$ & $\mathrm{MPa}$ \\
\hline Z\#7 & 4050.88 & 333.29 & 2.0 & 1.06 & 12.15 & 189 \\
Z\#8 & 4091.84 & 333.94 & 1.2 & 0.82 & 12.25 & 146 \\
Z\#9 & 3734.68 & 332.97 & 1.0 & 0.94 & 11.22 & 106 \\
Z\#10 & 3845.35 & 333.62 & 1.7 & 0.89 & 11.53 & 191 \\
Z\#12 & 3552.05 & 334.26 & 0.8 & 0.91 & 10.63 & 88 \\
Average & & & 1.34 & 0.92 & 11.56 & 144 \\
Variance & & & $0.17 \mathrm{MPa}^{2}$ & 0.005 & $0.36 \mathrm{MPa}^{2}$ & $1764 \mathrm{MPa}^{2}$ \\
Standard deviation & & & 0.41 & 0.07 & 0.6 & 41.9 \\
\hline \hline
\end{tabular}

In Table 2 stress and strain at the end of the elastic deformation is given, as well as the ultimate strength at failure. A total of seven tests were carried out of which five were considered as valid. Tests were considered invalid, for instance, when the failure occurred the clamps.

The compression modulus was calculated for the linear elastic deformation at the beginning of the tests up to the end of the elastic behavior. 
The poisson number was derived using several sections over the sample and averaging the results of the sections. The results for one section were also averaged over the whole section length. Values from the sample edges were neglected. In combining the results of the longitudinal and the transverse strains, the poisson numbers can be calculated. The evaluation of the poisson number was done for the linear elastic portion only.

In Figure 3 the images of the optical strain measurements are shown for the testing of sample Z\#8 with the sections used for calculating the transverse strains. The longitudinal strains were calculated with the test machine displacement data.

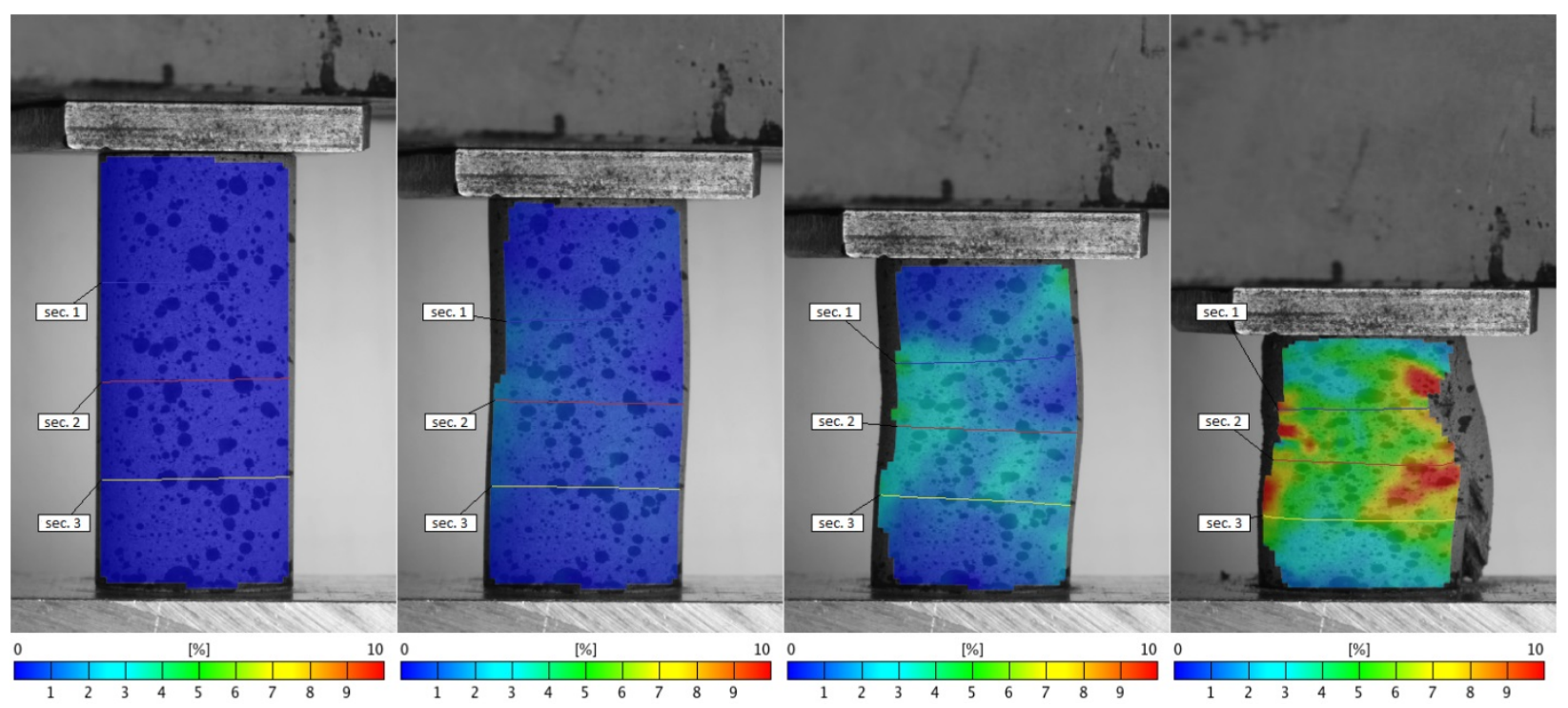

Figure 3: Transverse strain of sample Z\#8 at progressing times.

In Figure 4 the graphs of the longitudinal and transverse strains of samples Z\#7 and Z\#8 are shown along with the resulting poisson numbers. Table 3 lists the results for all other samples.
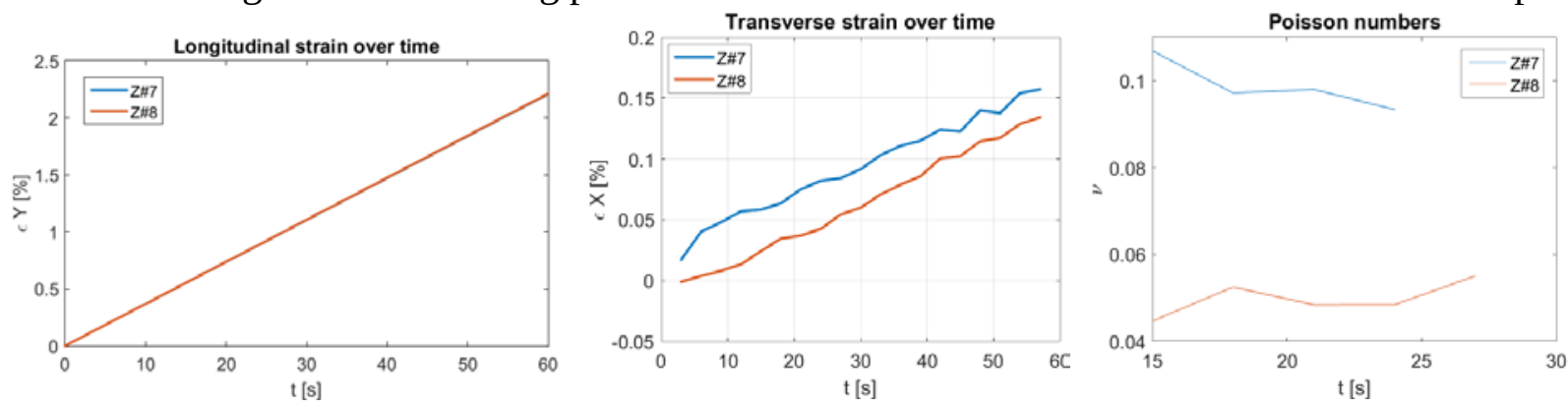

Figure 4: Longitudinal, transverse strain and derived poisson numbers for samples Z\#7 and Z\#8. 
Table 3: Poisson number from compression tests.

\begin{tabular}{|c|c|c|c|c|c|c|c|c|}
\hline $\mathrm{t} / \mathrm{sec}$ & 9 & 12 & 15 & 18 & 21 & 24 & 27 & $\begin{array}{l}\text { Average per } \\
\text { sample }\end{array}$ \\
\hline Z\#7 & & & 0.1069 & 0.0972 & 0.098 & 0.0933 & & 0.0988 \\
\hline Z\#8 & & & 0.0447 & 0.0525 & 0.0484 & 0.0484 & 0.055 & 0.0498 \\
\hline Z\#9 & & 0.067 & 0.074 & 0.0747 & 0.0771 & 0.0836 & 0.0918 & 0.078 \\
\hline Z\#10 & & 0.0386 & 0.0442 & 0.0414 & 0.0451 & & & 0.0446 \\
\hline Z\#12 & 0.034 & 0.0404 & 0.0554 & 0.0473 & 0.048 & 0.058 & & 0.0471 \\
\hline \multicolumn{8}{|c|}{$\begin{array}{l}\text { Average all samples } \\
\text { Variance }\end{array}$} & $\begin{array}{c}0.0637 \\
0.000454 \\
0.0213\end{array}$ \\
\hline
\end{tabular}

The poisson numbers achieved from the compression tests were later used to determine the actual failure strain and stress under tension load via numerical simulation.

\section{COMPRESSION TESTS PARALLEL TO THE FIBER DIRECTION}

For the compression tests on samples with the main fiber direction in the load direction the sample geometry was a rectangular block of $20 \times 20 \times 40 \mathrm{~mm}$. In this case the samples were cut out of a machined block of $40 \mathrm{~mm}$ thickness using a circular saw with diamond-tipped blade. The length of the samples of $40 \mathrm{~mm}$ was actually the clamped length in the test machine.

The tests were conducted in the same Zwick-Roell $250 \mathrm{kN}$ mechanical test machine as the preceding compression tests. The test velocity was $1 \mathrm{~mm} / \mathrm{min}$ with displacement as the control parameter. A pre-load of $5 \mathrm{~N}$ was applied. The tests were carried out in the mechanical test lab in controlled conditions in one step. Of 12 tests conducted, 9 were accepted as valid.

In Figure 6 the results are given in the form of load-displacement graphs. The behavior of the samples is very different from the compression tests normal to the main fiber direction. The samples mostly exhibit a brittle failure with very little or almost no plastic deformation. The elastic strain is limited to a value of approximately $1.75 \%$.

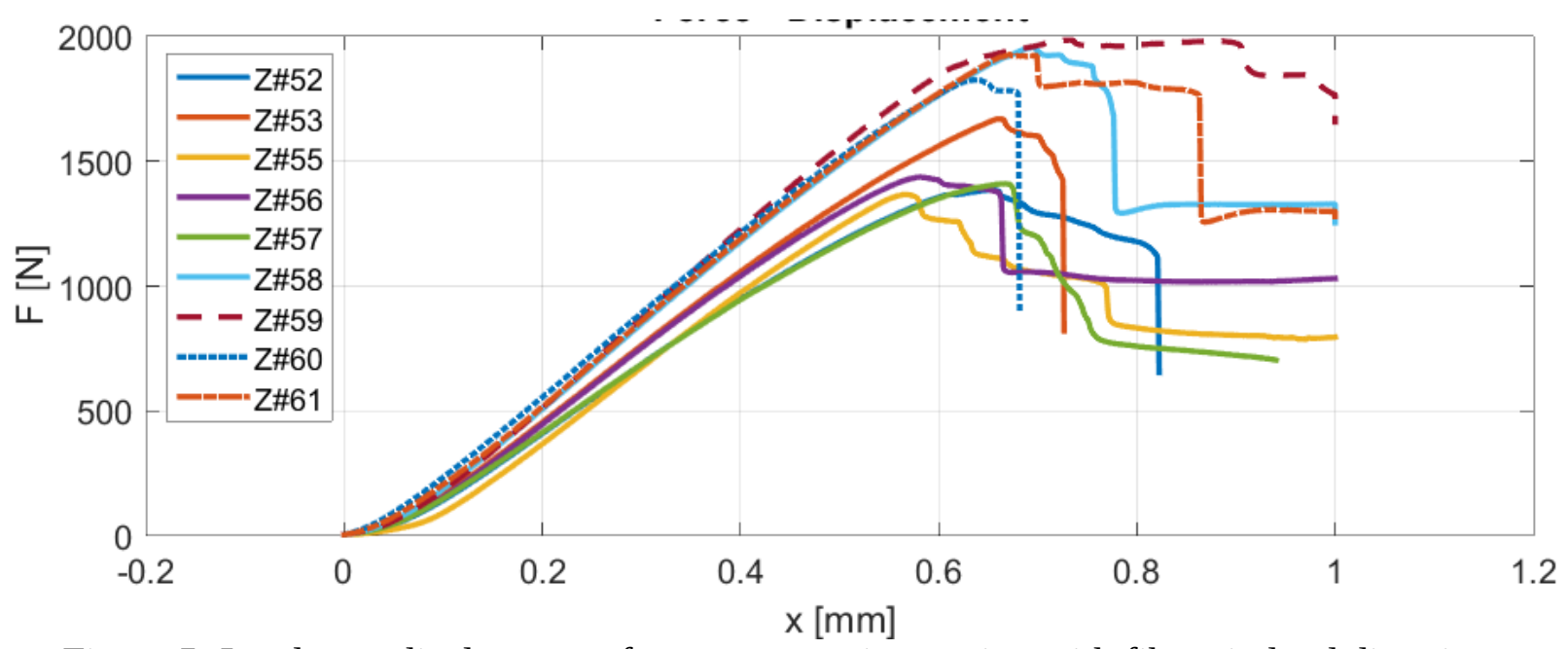

Figure 5: Load over displacement from compression testing with fibers in load direction. 
Table 4: Compression test results with fibers in load direction.

\begin{tabular}{cccccc}
\hline \hline Sample & $\mathrm{F}_{\mathrm{m}}$ & $\mathrm{A}_{0}$ & $\sigma_{\mathrm{c}, \mathrm{e}}$ & $\varepsilon_{\mathrm{c}, \mathrm{m}}$ & $\mathrm{E}_{\mathrm{c}, \mathrm{e}}$ \\
\hline & $\mathrm{N}$ & $\mathrm{mm}^{2}$ & $\mathrm{MPa}$ & & $\mathrm{MPa}$ \\
\hline Z\#52 & 1386.34 & 390.06 & 3.55 & 0.0164 & 275.64 \\
Z\#53 & 1669.62 & 392.44 & 4.25 & 0.0166 & 304.94 \\
Z\#55 & 1365.97 & 392.63 & 3.48 & 0.0142 & 300.73 \\
Z\#56 & 1437.02 & 393.42 & 3.65 & 0.0146 & 295.71 \\
Z\#57 & 1409.54 & 395.41 & 3.56 & 0.0169 & 263.24 \\
Z\#58 & 1957.05 & 391.64 & 5.00 & 0.0175 & 331.54 \\
Z\#59 & 1984.92 & 391.44 & 5.07 & 0.0184 & 356.86 \\
Z\#60 & 1826.37 & 394.02 & 4.64 & 0.0160 & 323.40 \\
Z\#61 & 1927.52 & 387.08 & 4.98 & 0.0169 & 338.63 \\
Average & & & 4.24 & & $310 \mathrm{MPa}$ \\
Variance & & & $0.424 \mathrm{MPa}^{2}$ & & $815 \mathrm{MPa}^{2}$ \\
Standard deviation & & & 0.651 & & $28.6 \mathrm{MPa}$ \\
\hline \hline
\end{tabular}

The average compression strength with the load in direction of the main fiber direction is 4.24 MPa. This is more than three times the value obtained for the load normal to the main fiber direction. Young's modulus is calculated as the secant modulus for the elastic portion of the displacement. It is on average $310 \mathrm{MPa}$ and two times the value obtained for the load normal to the main fiber direction.

\section{SHEAR TESTS}

Shear tests were carried out to determine the shear strength in the plane of the main fiber direction, i.e. in the preform in-plane direction. Rectangular blocks of $60 \times 60 \times 20 \mathrm{~mm}$ size were cut. In order to be able to transfer the mechanical load into the samples, aluminum plates were bonded on opposite faces of the samples. The overall size of the samples including the aluminum plates was $80 \times 80 \times 30 \mathrm{~mm}$. The fixture that was used consisted of two supporting angles to keep the specimen in the desired position and prevent tilting during the test. On one side the aluminum plate of the specimen was supported by a steel block, the other aluminum plate was placed under the plunger of the test machine.

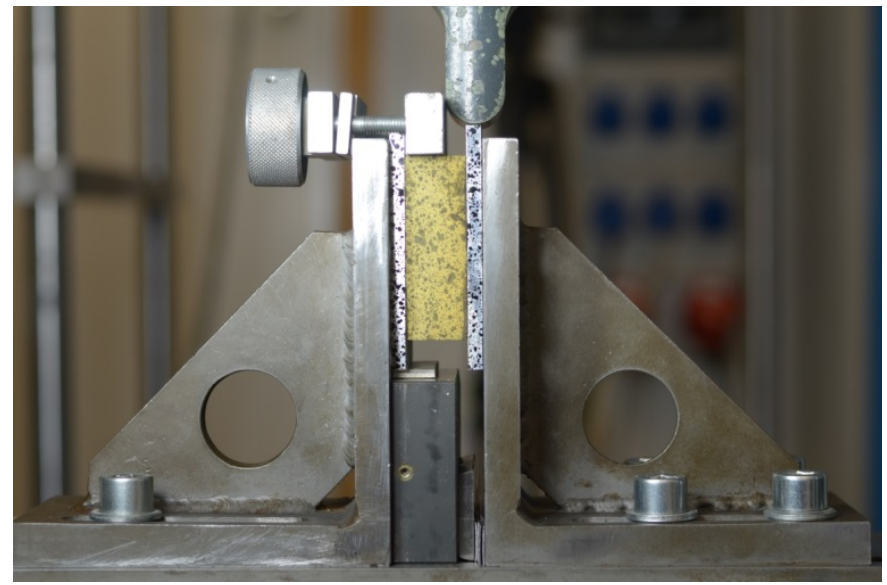

Figure 6: Setup of the shear tests.

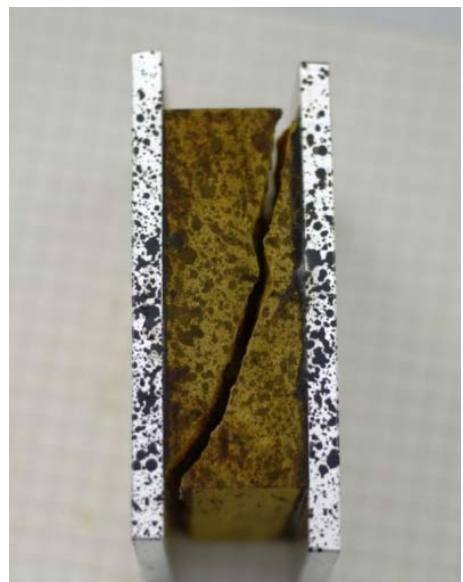

Figure 7: Typical fracture pattern of the shear specimens (Z\#75).

The tests were carried out in a Zwick-Roell $100 \mathrm{kN}$ test machine. The test velocity was $0.5 \mathrm{~mm} / \mathrm{min}$. The tests were carried out in one step with an initial pre-load of $10 \mathrm{~N}$. Eight tests 
with seven valid results were performed. Z\#78 was considered invalid because the failure was clearly in the adhesive layer.

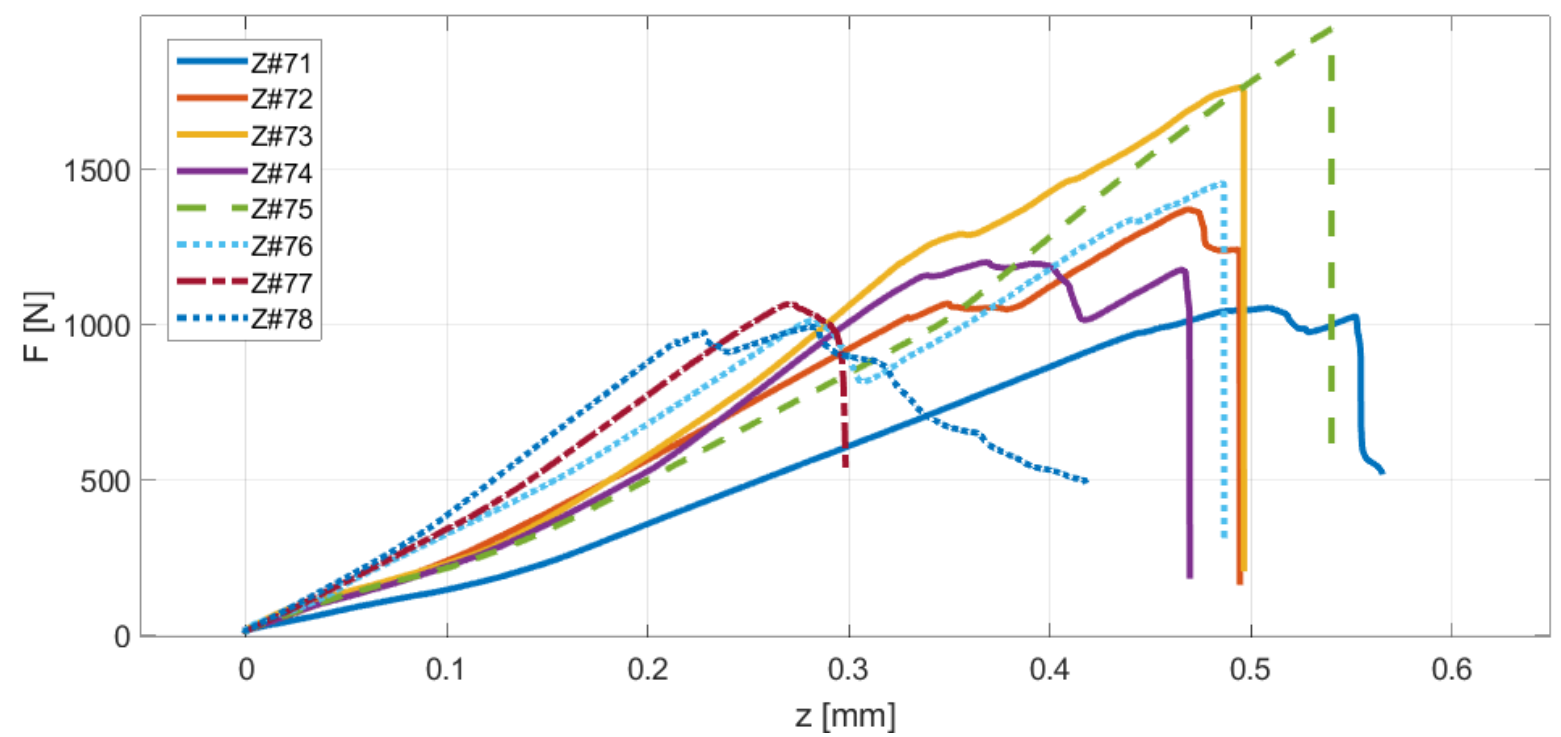

Figure 8: Load - displacement graphs of the shear tests.

The typical fracture behavior is shown in Figure 8 with the crack running slightly angled through the complete sample. Since the samples had a big relevant cross section of $60 \times 60 \mathrm{~mm}$, it was expected that variations in the properties would be equaled to a certain amount. However, despite the comparatively large samples there was a large variation in terms of the achieved strain and strength values. In addition, at a displacement value of around $0.1 \mathrm{~mm}$ there was a characteristic bend in the load-displacement graphs that is possibly due to a not-so-perfect setup with a little movement of the samples. Although the samples had been prepared with the dot pattern, the optical measurement was not carried out for the shear tests which could have given a hint if there was an unwanted sample movement or not. The results of the shear tests are listed in Table 5. The average shear strength is $0.39 \mathrm{MPa}$ and the average shear modulus in this direction is $17.74 \mathrm{MPa}$.

Table 5: Single and averaged shear test results

\begin{tabular}{ccccc}
\hline \hline Sample & $\mathrm{F}_{\mathrm{m}}$ & $\mathrm{A}_{0}$ & $\tau_{\mathrm{m}}$ & $\mathrm{G}$ \\
\hline & $\mathrm{N}$ & $\mathrm{mm}^{2}$ & $\mathrm{MPa}$ & $\mathrm{MPa}$ \\
\hline Z\#71 & 1051.06 & 3598.8 & 0.29 & 11.5 \\
Z\#72 & 1368.60 & 3594.6 & 0.38 & 16.3 \\
Z\#73 & 1761.23 & 3604.8 & 0.49 & 19.8 \\
Z\#74 & 1198.66 & 3603.0 & 0.33 & 18.3 \\
Z\#75 & 1948.76 & 3604.8 & 0.54 & 19.8 \\
Z\#76 & 1451.17 & 3608.4 & 0.40 & 16.5 \\
Z\#77 & 1062.97 & 3598.2 & 0.30 & 22.0 \\
Average strength & & & $0.39 \mathrm{MPa}$ & \\
Variance & & & $0.00777 \mathrm{MPa}{ }^{2}$ & \\
Standard deviation & & & $0.088 \mathrm{MPa}$ & \\
\hline Average modulus & & & $17.74 \mathrm{MPa}$ & \\
Variance & & & $13.01 \mathrm{MPa}$ & \\
Standard deviation & & & $3.60 \mathrm{MPa}$ & \\
\hline \hline
\end{tabular}




\section{TENSILE TESTS WITH THE LOAD IN THE MAIN FIBER DIRECTION}

For the tensile testing the specimen geometry was waisted towards the middle of the sample to reduce the cross section area and enforce failure in the waisted region far from the load introduction. The geometry was selected following the test standard DIN EN 658-1. The tests were carried out in a Zwick-Roell $100 \mathrm{kN}$ test machine. The test velocity was $0.5 \mathrm{~mm} / \mathrm{s}$. The tests were carried out in one step with an initial pre-load of $5 \mathrm{~N}$. Nine tests with nine valid results were carried out.

For the test evaluation, both the machine data as well as the data from the optical strain measurement was used. In Figure 10 the outline of the sample shape is depicted along with a sample prepared with the dot pattern and an image of a sample under load and after fracture.

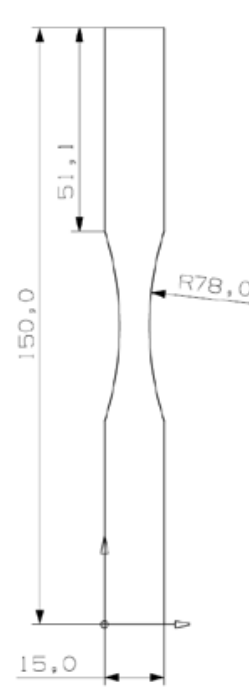

a)

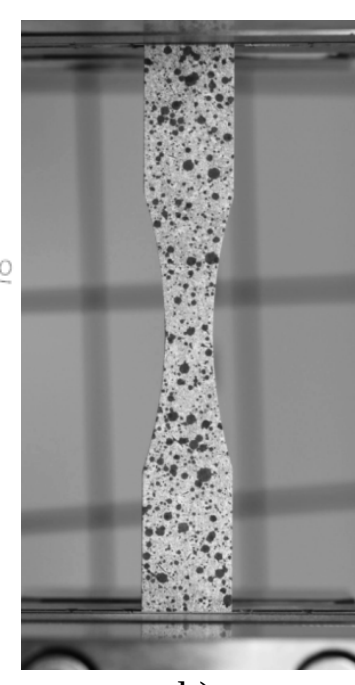

b)

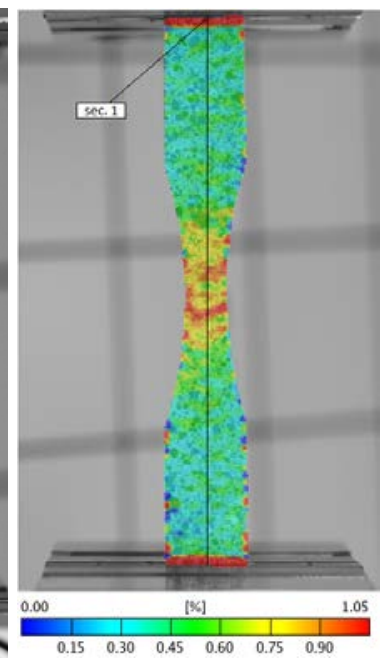

c)

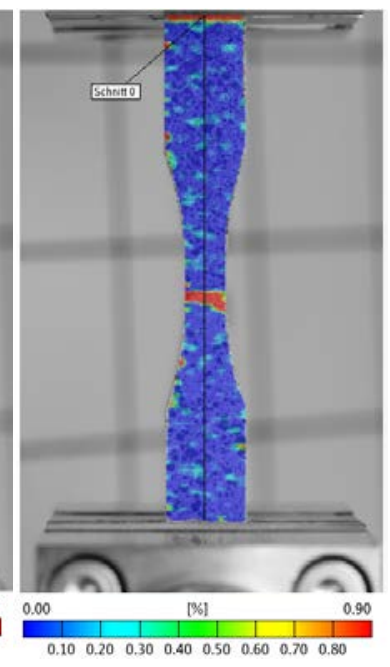

d)

Figure 9: a) Shape of the tensile samples b) sample with dot pattern c) sample under load d) sample after fracture

In Table 6 the typical geometric data of the tensile samples is given. The load displacement graphs of the tensile tests are shown in Figure 11. It is evident that the failure was brittle without any plasticity in all cases. In addition there was a relatively large variation between the samples concerning both the slope of the load graph as well as the fracture load.

Table 6: Typical geometric data of the tensile samples

\begin{tabular}{cccccc}
\hline \hline Total length & Clamped length & Width ends & Width center & Thickness & Radius \\
\hline $\mathrm{mm}$ & $\mathrm{mm}$ & $\mathrm{mm}$ & $\mathrm{mm}$ & $\mathrm{mm}$ & $\mathrm{mm}$ \\
\hline 150 & 100 & 15 & 7.5 & 6 & 78 \\
\hline \hline
\end{tabular}




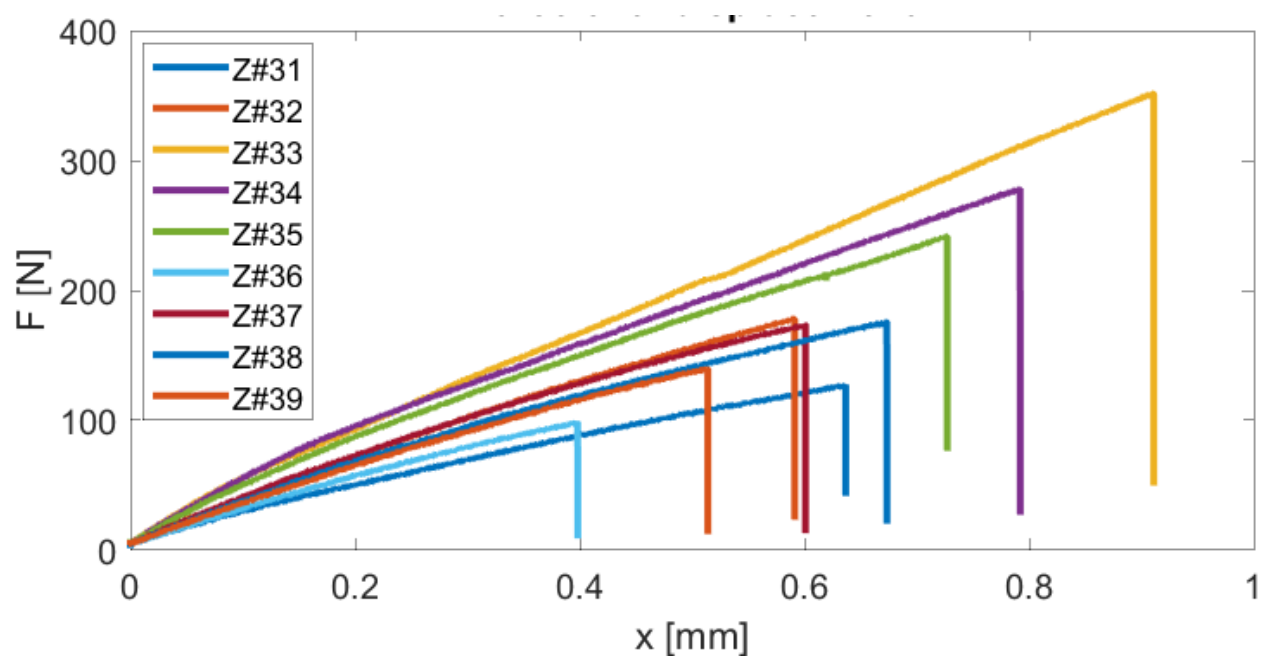

Figure 10: Force-displacement graphs of the tensile tests.

Table 7: Results of tensile tests parallel to fiber direction applying nominal cross section areas.

\begin{tabular}{cccccc}
\hline Sample & $\mathrm{F}_{\mathrm{m}}$ & $\mathrm{A}_{0}$ & $\sigma_{\mathrm{t}, \mathrm{nom}}$ & $\varepsilon_{\mathrm{t,m}}$ & $\varepsilon_{\mathrm{t,m}}$ \\
\hline & $\mathrm{N}$ & $\mathrm{mm}^{2}$ & $\mathrm{MPa}$ & $\mathrm{mm}$ & $\%$ \\
\hline Z\#31 & 127.445 & 44.218 & 2.88 & 0.636 & 0.60 \\
Z\#32 & 178.562 & 47.760 & 3.74 & 0.589 & 0.60 \\
Z\#33 & 352.053 & 46.085 & 7.64 & 0.911 & 0.89 \\
Z\#34 & 278.556 & 44.252 & 6.29 & 0.792 & 0.83 \\
Z\#35 & 242.184 & 47.561 & 5.09 & 0.727 & 0.82 \\
Z\#36 & 98.861 & 44.506 & 2.22 & 0.398 & 0.45 \\
Z\#37 & 174.206 & 44.863 & 3.88 & 0.601 & 0.68 \\
Z\#38 & 175.703 & 45.491 & 3.86 & 0.672 & 0.75 \\
Z\#39 & 140.196 & 46.414 & 3.02 & 0.514 & 0.57 \\
Average & 205.04 & 45.87 & 4.47 & 0.65 & 0.70 \\
Variance & $5798.54 \mathrm{~N}^{2}$ & $1.55 \mathrm{~mm}^{4}$ & $2.77 \mathrm{MPa}^{2}$ & $0.02 \mathrm{~mm}^{2}$ & 0.02 \\
Standard deviation & 76.15 & 1.25 & 1.66 & 0.15 & 0.14 \\
\hline \hline
\end{tabular}

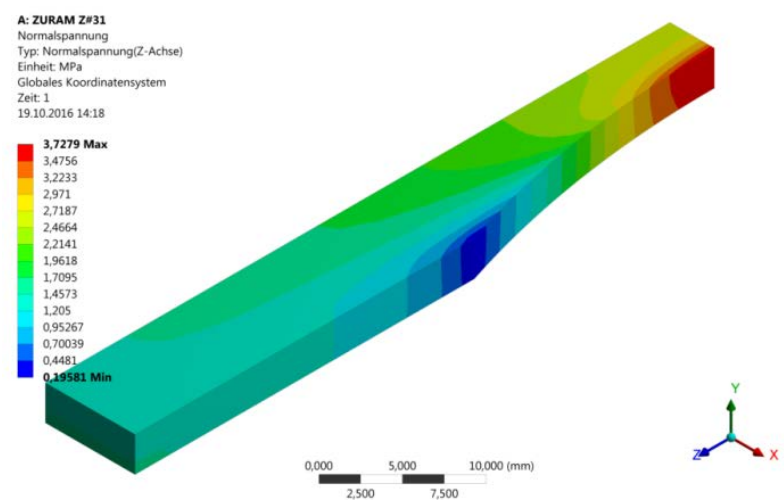

Figure 11: Stress distribution in the sample.
Using the nominal cross section area in the waisted sample section yields a tensile strength between 2 and $7 \mathrm{MPa}$. As already indicated, this seemed not to be appropriate and indeed, a numerical simulation which was set up in order to support the investigation shows this. A stress analysis with the data available so far indicated immediately that the stress is not uniform across the sample but concentrated near the edges of the waisted region. A stress concentration of this kind in waisted samples is usually relaxed by plasticity, when e.g. 
metals are tested, until there is a uniform stress across the section. However, in this case, the material is purely brittle, so the stress concentration had to be accounted for. The required material parameters for the simulation were taken from the compression and shear tests that had been carried out earlier.

Therefore, the stress had to be determined from the local strain from the optical measurements. Images were taken continuously during the tests, so the last image before fracture was used to determine the failure strain. In Figure 13 the strain distribution over sample Z\#31 is shown with the results of three evaluation sections. The evaluation section in the waisted region was used to determine the failure strain, which was $1.07 \%$ in this case; at the sample edge. This is a considerable difference to the strain value of $0.6 \%$ which is resulting when the machine displacement data is used to calculate a strain value which is integrated over the whole sample.
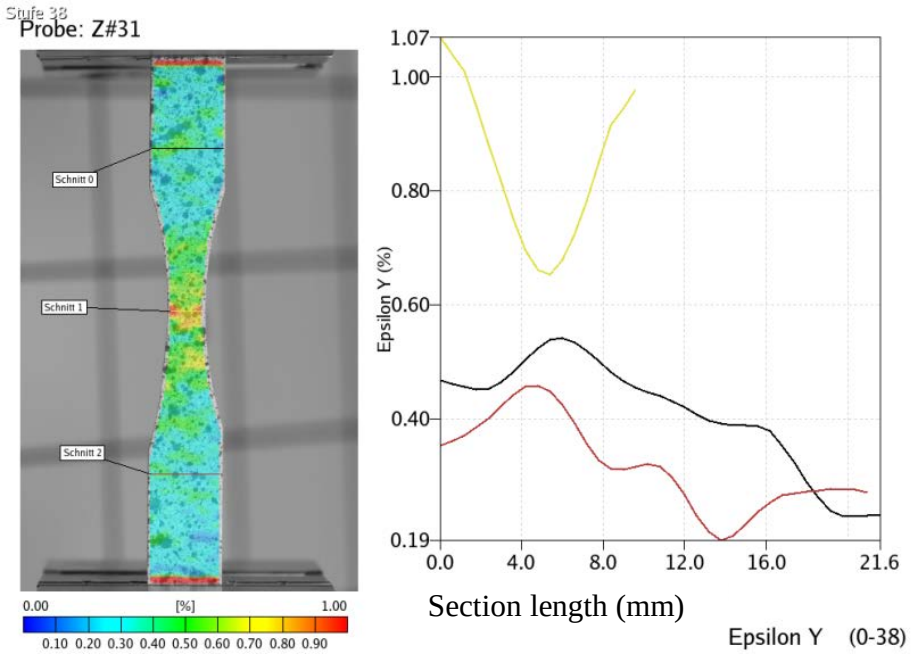

Figure 12: Determination of the local failure strain.

In order to be able to calculate the stress from the local strain values, Young's modulus had to be known. The modulus had been measured before on the compression samples. However, it had been found that there is a relatively large variation in the data, so for that reason it was decided not to use the average modulus value from the compression tests but to determine the individual modulus for each tensile sample. To do that, an iterative approach was used based on simulation and using the machine displacement data which in itself was considered reliable as an integral value. The tensile simulation was carried out with the final displacement value as the target quantity and the force of the fracture load given; then the modulus was varied until the correct displacement number was achieved. This procedure was carried out for every sample to generate the individual modulus for each sample. With the individual modulus and the local failure strain for each sample, the individual failure stress could be calculated.

Table 8: Comparison between actual and nominal failure stress for tensile tests.

\begin{tabular}{cccccc}
\hline \hline Sample & $\sigma_{\mathrm{t}}$ & $\sigma_{\mathrm{t}, \mathrm{FE}}$ & $\mathrm{E}_{\mathrm{t}, \mathrm{FE}}$ & $\sigma_{\mathrm{t}, \text { nom }}$ & $\alpha$ \\
\hline Z\#31 & $\mathrm{MPa}$ & $\mathrm{MPa}$ & $\mathrm{MPa}$ & $\mathrm{MPa}$ & Ratio local/nominal \\
Z\#32 & 3.49 & 3,72 & 327 & 2.88 & 1.21 \\
Z\#33 & 4.14 & 5,09 & 391 & 3.74 & 1.11 \\
Z\#34 & 8.73 & 11,66 & 582 & 7.64 & 1.14 \\
Z\#35 & 6.49 & 8,97 & 481 & 6.29 & 1.03 \\
Z\#36 & 4.28 & 6,94 & 386 & 5.09 & 0.84 \\
Z\#37 & 3.35 & 2,87 & 302 & 2.22 & 1.51 \\
Z\#38 & 3.59 & 5,1 & 345 & 3.88 & 0.93 \\
Z\#39 & 3.50 & 4,99 & 315 & 3.86 & 0.91 \\
Average & 4.12 & 3,92 & 322 & 3.02 & 1.36 \\
Variance & 4.63 & 5.91 & 383 & 4,29 & 1.12 \\
Standard deviation & $2.91 \mathrm{MPa}^{2}$ & $7.07 \mathrm{MPa}^{2}$ & $7640 \mathrm{MPa}^{2}$ & $2.71 \mathrm{MPa}^{2}$ & \\
\hline \hline
\end{tabular}


In Table 9 the individual failure stresses for each sample are compared against the nominal values and the results from the numerical simulation. The parameter $\alpha$ is determined as the ratio between the local stress calculated with the optical strain measurement and the stress determined with the nominal sample cross section and the applied force. On average, $\alpha$ has the value 1.12 which means that the tensile strength is on average $12 \%$ higher than what the nominal testing approach would suggest.

Table 9: Poisson numbers from tensile testing.

\begin{tabular}{ll}
\hline \hline Sample & $v_{\mathrm{xy}}$ \\
\hline & - \\
\hline Z\#31 & 0.29 \\
Z\#32 & 0.22 \\
Z\#33 & 0.39 \\
Z\#34 & 0.45 \\
Z\#35 & 0.32 \\
Z\#36 & 0.25 \\
Z\#37 & 0.29 \\
Z\#38 & 0.28 \\
Z\#39 & 0.24 \\
\hline \hline
\end{tabular}

Also for the tensile tests, the poisson numbers were determined and are listed for each sample in Table 10. The numbers are higher than those given in Table 3 for the compression testing because here, the two "strong" directions are related which lie both in the main fiber directions. Figure 14 shows how the poisson numbers were determined. Three sections in the un-waisted region of the sample, both in the longitudinal and the transverse direction, were used to have averaged values for the strains, which were then put in relation to each other.
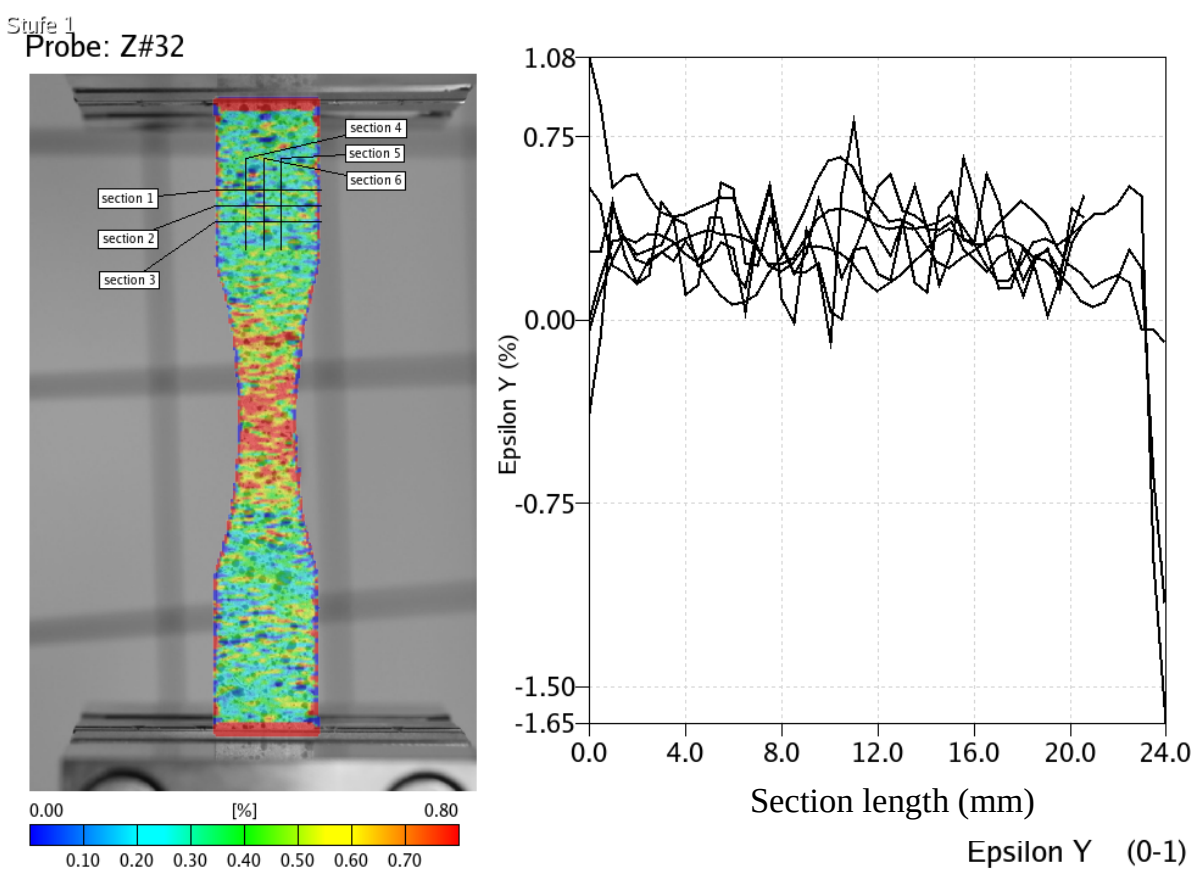

Figure 13: Determination of the poisson numbers in the tensile tests.

\section{TENSILE TESTS NORMAL TO FIBER DIRECTION}

The mechanical characterization described above had shown that the material shows a brittle failure behavior, except for the compression testing. Testing with the waisted samples had shown that the tapering of the cross section certainly keeps the fracture away from the sample ends, but it had also shown that additional considerations have to be made to account for the stress concentration which cannot be avoided due to the brittle nature of the material. 


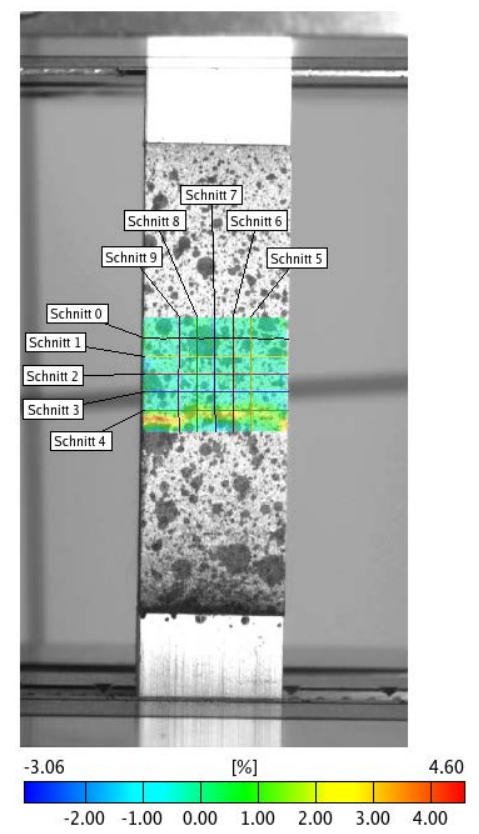

Figure 14: Tensile sample for testing normal to fibers.
Re-considering these things led to the decision to do the tensile testing in the direction normal to the main fiber direction with simple quadrilateral samples without tapering and to make an assessment for each test whether it can be regarded as acceptable or not considering the fracture location. In order to be able to introduce the load and clamp the samples, aluminium blocks were bonded to the sample ends. In Figure 15 a sample is shown right after fracture. The fracture is located far away from the clamps, so the test was considered acceptable. For these tests, five sections were evaluated in both the longitudinal and transverse directions to calculate the poisson numbers. In Table 11 the results of the tensile tests normal to the fibers are summarized. The average tensile strength is $0.76 \mathrm{MPa}$. The lowest measured value was $0.43 \mathrm{MPa}$ and the standard deviation has a value of 0.38 $\mathrm{MPa}$, which is exactly $50 \%$ of the strength. These numbers are quite low, so when a design is made, tensile stresses in the direction normal to the fibers have to be watched carefully.

Table 10: Results of tensile tests normal to fiber direction.

\begin{tabular}{cccccc}
\hline \hline Sample & $\mathrm{F}_{\mathrm{m}}$ & $\mathrm{A}_{0}$ & $\sigma_{\mathrm{t}, \text { normal }}$ & $\varepsilon_{\mathrm{t}}$ & $\mathrm{E}_{\mathrm{t}, \mathrm{n}}$ \\
\hline & $\mathrm{N}$ & $\mathrm{mm}^{2}$ & $\mathrm{MPa}$ & $\%$ & $\mathrm{MPa}$ \\
\hline Z\#41 & 303.508 & 213.28 & 1.42 & 1.03 & 137.00 \\
Z\#42 & 98.674 & 227.71 & 0.43 & 0.64 & 64.32 \\
Z\#43 & 102.362 & 228.16 & 0.45 & 0.62 & 68.98 \\
Z\#44 & 115.326 & 227.41 & 0.51 & 0.60 & 80.66 \\
Z\#45 & 110.858 & 227.86 & 0.49 & 0.62 & 74.46 \\
Z\#46 & 309.146 & 227.41 & 1.36 & 0.90 & 147.45 \\
Z\#47 & 143.041 & 227.41 & 0.63 & 0.84 & 71.34 \\
Z\#48 & 169.725 & 226.35 & 0.75 & 0.93 & 77.76 \\
\hline Average & 169.08 & 225.70 & 0.76 & 0.77 & 90.25 \\
Variance & $6756.93 \mathrm{~N}^{2}$ & $22.28 \mathrm{~mm}^{4}$ & $0.14 \mathrm{MPa}^{2}$ & 0.03 & $8938.58 \mathrm{MPa}^{2}$ \\
Standard deviation & 82.20 & 4.72 & 0.38 & 0.16 & 94.54 \\
\hline \hline
\end{tabular}

\section{RESULTS SUMMARY}

A total of five different test campaigns was carried out to determine the most important mechanical properties of the ZURAM material. Compression tests were done on samples with the load in parallel to the fiber direction and also perpendicular to the main fiber direction. The same was done in tensile loading, also in that case tests were done in parallel to the fibers and also in the direction normal to the fibers. For what concerns shear testing, only properties for the in-plane shear strength and the related shear modulus were measured. The shear properties orthogonal to that in the out-of-plane directions have yet to be determined. A summary of the average strength results and the corresponding modulus values for the different test cases is given in Table 12. 
Table 11: Summary of the strength and modulus results.

\begin{tabular}{lllll}
\hline \hline & Strength & & Modulus & \\
\hline & In-plane & Out-of-plane & In-plane & Out-of-plane \\
\hline MPa & MPa & MPa & MPa \\
\hline Tension & 5.91 & 0.76 & 383 & 90.25 \\
Sompression & 4.24 & 1.34 & 310 & 144 \\
\hline \hline
\end{tabular}

\section{CONCLUSION}

The mechanical properties of the ablative material ZURAM were determined. Tests were carried out in compression, shear and in tension. The material is produced using a carbon fiber preform with short chopped fibers, where the fibers are not oriented in a random way in every direction. In the plane of the preform plates there are more fibers oriented than in the direction normal to the plate. Therefore, the compression and tension tests were done using two different batches of samples with different orientation with respect to the fiber direction in the sample. In one batch the fibers were mainly oriented in the load direction and in the second batch the load was perpendicular to the main fiber direction.

First, elastic properties and strength values for compression and shear were determined. The compression tests were insensitive with regard to a load introduction influence. The shear tests mainly too, but in some cases the failure was clearly initiated by the adhesive layer, so the test had to be considered invalid for the determination of the strength.

Since the goal was not only to determine modulus and strength but also poisson numbers for simulation purposes, an optical method was applied to do so. Usually strain gauges would be used. However, for this type of material the influence of the strain gauge adhesive would be too dominant because it would create a local reinforcement falsifying the results. The application of the optical method proved to be very valuable. Local strain values could be measured and good data for the poisson numbers could be collected.

The tension tests with waisted (or dog-bone) samples show a non-uniform strain and stress distribution. In addition, the material does not show a pronounced plastic behavior under tension so that the stress concentration in the reduced-cross section area remains until failure and the simplified approach employing force and nominal cross section cannot be used. For that reason, the tests were evaluated with the optical method but also re-built numerically to establish the actual strain and stress at the failure location. A comparison between the nominal and the actual failure stress values for the waisted tension samples shows that the actual failure stress is roughly $12 \%$ higher.

Finally, also tension samples were produced and tested which had the fibers oriented normal to the load direction. These samples were again simple quadrilateral blocks. The reason for going back to that simple shape was that the tests with the waisted samples had shown that the failure is really fully brittle and the complex shape does not give a significant advantage in terms of the result quality.

The results of the tests are summarized in Table 12. In general it can be said that the strength of the material is quite low, as can be expected for a material of that composition. This result, plus the fact that there are relatively large variations in the data, suggest that in the design process of a heat shield great care is taken and lower boundary values should be used in order to have a reliable margin. In addition, these results also suggest that additional work be done to reduce the variations in the properties. First, the exact reasons for the property variations have to be determined, whether they are due to the carbon fiber preform or also due to factors in processing. 
NOMENCLATURE

\begin{tabular}{|c|c|}
\hline$A_{0}$ & Initial cross section area \\
\hline CALCARB & Trade name of carbon fiber insulation board \\
\hline CFRP & Carbon fiber reinforced plastic \\
\hline CMC & Ceramic matrix composite \\
\hline DIN & Deutsches Institut für Normung \\
\hline DLR & Deutsches Zentrum für Luft- und Raumfahrt (German Aerospace Center) \\
\hline DSLR & Digital single lens reflex \\
\hline $\mathrm{E}$ & Young's modulus \\
\hline $\mathrm{E}_{\mathrm{c}, \mathrm{e}}$ & Elastic compression modulus \\
\hline $\mathrm{E}_{\mathrm{t}, \mathrm{FE}}$ & Tensile Young's modulus as a result of finite element simulation \\
\hline $\mathrm{E}_{\mathrm{t}, \mathrm{N}}$ & Tensile Young's modulus normal to fiber direction \\
\hline EN & European Norm \\
\hline $\mathrm{F}_{\mathrm{m}}$ & Peak force \\
\hline G & Shear modulus \\
\hline $\mathrm{MPa}$ & Megapascal \\
\hline TPS & Thermal protection system \\
\hline ZURAM & Trade name of ablative DLR material \\
\hline$\alpha$ & $\begin{array}{l}\text { Ratio between stresses determined via local analysis and via applying } \\
\text { nominal cross section area }\end{array}$ \\
\hline$\sigma_{\mathrm{c}, \mathrm{e}}$ & Elastic compression stress \\
\hline$\sigma_{\mathrm{c}, \mathrm{p}}$ & plastic compression stress, ultimate compression failure strength \\
\hline$\sigma_{\mathrm{t}, \mathrm{FE}}$ & Tensile stress as a result of finite element simulation \\
\hline$\sigma_{\mathrm{t}, \mathrm{m}, \mathrm{t}}$ & Tensile stress for tapered specimen \\
\hline$\sigma_{\mathrm{t}, \mathrm{nom}}$ & Tensile stress applying nominal cross section area for waisted samples \\
\hline$\sigma_{\text {t,normal }}$ & Tensile stress normal to fibers \\
\hline$\varepsilon_{\mathrm{c}, \mathrm{e}}$ & Elastic compression strain \\
\hline$\varepsilon_{\mathrm{c}, \mathrm{m}}$ & Compression strain at peak load \\
\hline$\varepsilon_{\mathrm{t}, \mathrm{m}}$ & Tensile strain at peak load \\
\hline$v_{x, y}$ & Poisson number in direction $\mathrm{x}, \mathrm{y}$ \\
\hline$\tau_{\mathrm{m}}$ & Shear stress at peak load \\
\hline
\end{tabular}

\section{REFERENCES}

${ }^{1}$ Bertin, J., J., Hypersonic Aerothermodynamics, AIAA 1993, ISBN 978-1563470363.

${ }^{2}$ Curry, D., M., Space Shuttle Orbiter Thermal Protection System Design and Flight Experience, NASA Technical Memorandum 104773, 1993

${ }^{3}$ Mitcheltree, R., A., Kellas, S., Dorsey, J., T., Desai, P., N., Martin, C., J., A passive Earth-Entry Capsule for Mars Sample Return, AIAA 98-2851

${ }^{4}$ Milos, F., S., Galileo Probe Heat Shield Ablation Experiment, Journal of Spacecrafts and Rockets, 34, No. 6, 1997

${ }^{5}$ Lachaud, J., Cozmuta, I., and Mansou, N. N., Multiscale Approach to Ablation Modeling of Phenolic Impregnated Carbon Ablators, Journal of Spacecrafts and Rockets, 47, No. 6, 2010. 
${ }^{6}$ Tran, H. K., Johnson, C. E., Rasky, D. J., Hui, F. C. L., Hsu, M. T., Chen, Y. K., Phenolic Impregnated Carbon Ablators (PICA) for Discovery class missions, AIAA, Thermophysics Conference, 31 ${ }^{\text {st }}$, New Orleans, LA, June 17-20, 1996.

${ }^{7}$ Agrawal, P., Chavez-Garcia, J. F., Pham, J., Fracture in Phenolic Impregnated Carbon Ablator, Journal of Spacecraft and Rockets, Vol. 50, No. 4, July-August 2013, pp. 735-741

${ }^{8}$ Willcockson, W. H., Stardust Sample Return Capsule Design Experience, Journal of Spacecraft and Rockets, Vol. 36, No. 3, May-June 1999, pp. 470-474

${ }^{9}$ Loehle, S., Staebler, T., Reimer, T., and Cefalu, A., Photogrammetric Surface Analysis of Ablation Processes in High Enthalpy Air Plasma Flow, AIA A Journal, 53, No. 11, 2015.

${ }^{10}$ Reimer, T., Loehle, S., Oefele, R., Photogrammetric Surface Recession Measurements on Ablative Samples of Various Shape, Materials Science and Technology 2015, Oct. 4-8, 2015, Columbus, USA. 